\title{
An online pilates exercise program is effective on proprioception and core muscle endurance in a randomized controlled trial
}

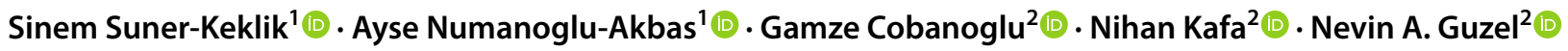

Received: 8 September 2021 / Accepted: 22 October 2021 / Published online: 30 October 2021

(c) The Author(s), under exclusive licence to Royal Academy of Medicine in Ireland 2021

\begin{abstract}
Background Proprioception is important for stability of body segments, postural control, and functionality. However, there are no studies in literature showing effects of online Pilates exercises that create proprioceptive inputs on vertebra on trunk proprioception.

Aims This study aims to reveal effect of online Pilates exercises conducted on trunk proprioception and core muscle endurance in healthy individuals.

Methods We included thirty-three healthy individuals between ages of 18 and 25 in study. Individuals were randomly divided into two groups. There were 17 individuals in Pilates group (PG), and 16 individuals in control group (CG). The PG was given online Pilates exercises by the physiotherapist in groups 3 days a week for 6 weeks, $1 \mathrm{~h}$ a day. There was no exercise program recommended for individuals in CG. We evaluated trunk proprioception with an inclinometer, core muscle endurance with three core endurance tests created by McGill, and prone bridge tests. All evaluations completed just before start of study and 2 days after 6 -week training.

Results Two groups had similar demographic characteristics, and there was no difference between baseline measurements $(p>0.05)$. While improvement observed in PG in trunk proprioception and all of core muscle endurance tests $(p<0.05)$, no statistically significant difference reported in CG $(p>0.05)$.

Conclusions We revealed that online Pilates exercises performed at mat level for 6 weeks in healthy individuals had positive effects on trunk proprioception and core muscle endurance with this study. Contribution of Pilates exercises to development of both muscular endurance and proprioceptive senses, even if performed at a distance, is important.
\end{abstract}

Keywords Core muscle endurance $\cdot$ Online exercise $\cdot$ Pilates $\cdot$ Proprioception

\section{Highlights}

- Online Pilates exercises had positive effects on trunk proprioception and core muscle endurance.

- Online Pilates exercises with a physiotherapist are a type of teleexercise that provides beneficial gains.

Sinem Suner-Keklik

s-suner@hotmail.com

Nihan Kafa

nkaratas@gazi.edu.tr

Nevin A. Guzel

natalay@gazi.edu.tr

1 Faculty of Health Sciences, Department of Physiotherapy and Rehabilitation, Sivas Cumhuriyet University, Sivas, Turkey

2 Faculty of Health Sciences, Department of Physiotherapy and Rehabilitation, Gazi University, Ankara, Turkey

\section{Introduction}

Tele-exercise services provided in the scope of telehealth services show beneficial effects and may be an important approach during the Coronavirus disease 2019 (COVID19) pandemic, where normal daily activities and health protection systems are disrupted or changed [1]. Innovative approaches are required to prevent functional decline in individuals under social distance and quarantine conditions. However, this is a requirement not only for pandemic conditions but also for individuals living in rural areas under normal conditions. Telehealth exercise programs are one way to provide physical activity [1]. Online Pilates exercises in the pandemic are one of the exercise approaches that will keep individuals active [2].

Pilates, developed by Joseph Pilates in the 1900s and gradually becoming widespread, is an exercise approach 
that aims to increase the endurance, strength, and flexibility of the core muscles and improve balance and dynamic postural control [3]. The primary goal in Pilates exercises is to increase the stability and strength of the transversus abdominus, multifidus, pelvic floor, and diaphragm muscles, which are known as core muscles, and to increase the flexibility of the lumbar region muscles, thus reducing the compression on the vertebra [4]. Because of the neutral spine position used during Pilates exercises, a balanced co-contraction can be created in the core muscles, thereby achieving mechanical stability in the lumbar vertebra and reducing the load on the vertebra [5].

Functionally, the core is a kinetic link that facilitates the transfer of torque and angular momentum between the upper and lower extremities in sports skills, professional skills, fitness activities, and daily living activities, in the execution of whole body movements [6]. Core muscles play an important role in reducing the risk of injury and stabilizing peripheral joints, especially during high physical activity [7]. Furthermore, core stability fires body mechanisms that allow for the maximization of the force exerted while minimizing the loads placed on the proximal joints $[8,9]$.

Proprioception is defined as the afferent entry of internal stimuli responsible for the stability of body segments, postural control, and several conscious senses, taken by proprioceptive fibers [10]. Proprioceptive signals are derived from mechanoreceptors located in ligaments, facet joints, intervertebral discs, and muscles. Among these structures, dense muscle spindles reported in paraspinal rotators are considered to be very important in controlling trunk movement [11]. Any deficiency in proprioception will affect the quality of movement because the ability to control trunk movement is necessary to establish the correct movement pattern [11].

Previous studies have shown the effects of the Pilates exercise programs on core muscle endurance using different methods [12-15]. However, there are no studies showing the effects of Pilates exercises, which are based on core muscle activity and create proprioceptive inputs on the vertebra, on trunk proprioception. Moreover, there is no other study in the literature that demonstrates the effectiveness of online Pilates exercises for healthy individuals within the scope of telehealth services. For these reasons, this study aims to investigate the effect of online Pilates training on trunk proprioception and core muscle endurance in healthy individuals.

\section{Materials and methods}

\section{Participants}

We conducted the study in Sivas Cumhuriyet University Faculty of Health Sciences, Department of Physiotherapy and Rehabilitation. Ethical approval obtained from Sivas
Cumhuriyet University, Non-Interventional Clinical Research Ethics Committee with the decision number 2018-018/23 dated 26.02.2018. This study has been conducted in accordance with the principles set forth in the Helsinki Declaration.

In the study, we included healthy volunteers between the ages of 18 and 25 and excluded individuals with vertebral pathology; with a history of pain, surgery, injury, or trauma in the lumbar region; and those with a neurological, systemic, or degenerative disease. We designed the study as a randomized, controlled, single-blind study. In addition, individuals who participated in a regular exercise program for the last 6 months were excluded. We used a computer program for randomization and placed the individuals who completed the first evaluation in the Pilates group (PG) or control group (CG) randomly. We explained the purpose and content of the study to the participants before the study. Furthermore, the participants signed an informed consent form that they would participate in the study voluntarily.

\section{Procedures}

We assessed the participants by an experienced physiotherapist, who was blind to the randomization, at the start of the study and 2 days after the 6-week training. The group to which they depended was not disclosed to the participants until the end of the baseline evaluation. We performed the Pilates exercises online, under the supervision of another certified physiotherapist with 13 years of experience. We asked the individuals not to inform the evaluator of their involvement in the training during the last evaluation.

\section{Outcome measurements}

We recorded demographic information (age, body weight, height, body mass index) of the participants.

We performed the evaluation of trunk proprioception by the active angle repetition test in a standing position using Dualer IQ Digital Inclinometer (J-Tech Medical, Midvale, UT, USA). One part of the inclinometer placed on the first lumbar vertebra and the other part on the sacrum [16]. The test started in an upright position. We asked the individuals to flex the trunk until reaching the target angle of $30^{\circ}$ in the sagittal plane and to maintain this position for $3 \mathrm{~s}$ then to come back to an upright position [17]. After the target angle was felt by the individuals three times in total, we asked the individuals to identify the perceived target angle three times as accurately as possible. The difference between the target angle perceived by the individuals and the angle found again by the individuals was averaged [18].

We evaluated the core muscle endurance by using three core endurance tests created by McGgill and the prone bridge test. The McGgill endurance tests are the trunk flexor test, the trunk extensor test, and the side bridge test. We 
performed a trunk flexor test with the trunk at $60^{\circ}$ flexion and knees and hips at $90^{\circ}$ flexion. The arms were crossed over the chest and individuals were asked to maintain this position for as long as possible. We performed a trunk extensor test in a prone position on the treatment table. The pelvis, hips, and knees were fixed on the treatment table, up to the spina iliaca anterior superior. We asked individuals to maintain a horizontal body position for as long as possible, with arms crossed over their chests. We performed the side bridge test on the mat, on the dominant and non-dominant sides, respectively, while lying down. The body weight of the participants was supported only by the lower elbows and feet while lifting their hips up on the mat. The test was stopped when the side-lying position was lost or the hips returned to the mat [19]. We performed a prone bridge test on the mat in the prone position and with support from the elbows. The elbows of the participants were placed under their shoulders, leaving a narrow space between their feet. We asked them to raise their hips and torso on their forearms and toes and to maintain a straight position. All core endurance tests terminated when positions were distorted. Measurement results were recorded in seconds [20].

\section{Intervention}

Pilates training was done by a certified and 13-year experienced physiotherapist and lasted a total of 6 weeks, 3 days a week for $1 \mathrm{~h}$. Exercises were performed online because of the pandemic. Microsoft Teams program was used to perform the exercises online. We divided the individuals in the Pilates exercise group into two smaller groups of 10 and 11 to verify whether they correctly did the exercises.

Pilates practitioners usually practice a simple series of exercises that include repetitive, low-intensity flexibility and muscular endurance exercises, with muscular movements in the abdominal, lower back, hips, and thighs [3]. In this study, we organized a program to include $10 \mathrm{~min}$ of warmup, $40 \mathrm{~min}$ of Pilates exercises, and $10 \mathrm{~min}$ of cooling and stretching exercises, and the exercises were done in 10 repetitions. The Pilates exercise program included the following exercises: hundreds, shoulder bridge, clam, sidekick, arm opening, abdominal preparation, one leg stretch, breaststroke preparations, cobra, swimming, and oblique roll-up. During the Pilates exercises, we described the exercises with different visual simulation techniques, and exercises were done together with Pilates breathing. We instructed the subjects to breathe through the nose before starting the movement and to complete the movement while exhaling through their teeth by contracting their lips [21]. No exercise recommendations were made for the control group, and individuals were asked to continue their routine activities.

\section{Data availability}

The data associated with the paper are not publicly available but are available from the corresponding author on reasonable request.

\section{Statistical analysis}

We performed statistical analysis by using SPSS software, version 21 (SPSS Inc. Chicago, IL, USA). The normal distribution of variables was determined using histograms, probability plots, and a Shapiro-Wilk test. Because of an abnormal distribution, median and interquartile range (IQR) were used for descriptive statistics. We used a Mann-Whitney U test to compare baseline and change values between groups. We used Wilcoxon Test for comparing baseline values within the group and values after 6 weeks. The level of significance was set at $p<0.05$ for all analyses. The effect sizes were evaluated according to Cohen's $d$ standards within the pre-post differences. Effect size results were interpreted as small $(\geq 0.2)$, medium $(\geq 0.5)$, or large $(\geq 0.8)$ according to guidelines [22].

\section{Results}

Within the scope of the study, we invited 44 healthy individuals for evaluation. Participants who did not come to the final measurement and did not complete the Pilates training because of personal reasons were excluded from the study. Consequently, 17 individuals from PG and 16 individuals from CG completed the study. Figure 1 shows the CONSORT flow diagram showing the participants in the study.

In the post hoc power analysis for the study, the effect size calculated considering the proprioception values was 1.041. When 17 individuals were included in PG and 16 individuals were included in CG, we calculated that the power of the study was 0.89 .

The two groups had similar characteristics in terms of demographic characteristics $(p>0.05$, Table 1$)$, and there was no difference between baseline measurements $(p>0.05$, Table 2).

In all of the proprioception sense and core muscle endurance tests, although the exercises were performed remotely online, PG was improved $(p<0.05$, Table 2$)$, while there was no statistically significant difference in CG $(p>0.05$, Table 2). Since we compared the groups in terms of changes, there was no difference between the two groups in terms of proprioception sense ( $p>0.05$, Table 2$)$, but there was a difference in other parameters $(p<0.05$, Table 2). 


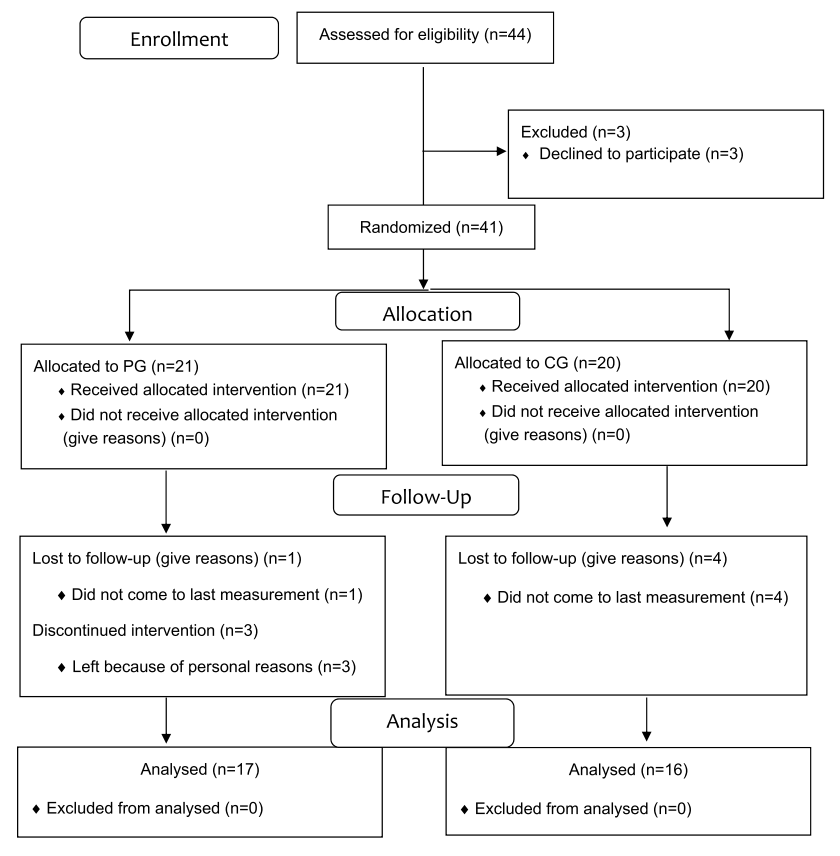

Fig. 1 CONSORT flowchart showing participation in the study

\section{Discussion}

This study, which we think is the first to investigate the effect of online Pilates exercise programs on trunk proprioception, has shown that a 6-week online Pilates exercise program is effective in improving trunk proprioception and core muscle endurance.

Proprioception plays an important role in motor control, and purposeful action is not possible without proprioceptive feedback [23]. A study examining the influence of trunk proprioception from a postural position in healthy individuals indicated that a decreased perception of the joint position may increase the risk of low back pain or injury [24]. This reveals the requirement for exercises that improve trunk proprioception. A study investigating the effects of 5-week Pilates exercises on dynamic balance demonstrated that, although proprioceptive sensation was not evaluated, providing feedback with verbal and tactile cues to correct erroneous movement patterns during the

Table 1 Demographic characteristics of the participants

\begin{tabular}{llll}
\hline & PG $(\boldsymbol{n}=\mathbf{1 7})$ & CG $(\boldsymbol{n = 1 6})$ & $\boldsymbol{p}$ \\
\hline Age (years) & $22(20-23)$ & $20.5(20-22)$ & 0.407 \\
Body weight $(\mathrm{kg})$ & $58(54-68)$ & $59(55-67)$ & 0.787 \\
Height $(\mathrm{cm})$ & $164(160-170)$ & $167.5(164-171)$ & 0.406 \\
BMI $\left(\mathrm{kg} / \mathrm{m}^{2}\right)$ & $20.9(19.31-23.3)$ & $21.15(19.36-24.17)$ & 0.773 \\
\hline
\end{tabular}

Data are presented as Median (IQR). ${ }^{*} p<0.05, P G$ Pilates group, $C G$ control group, $B M I$ body mass index exercises may have increased kinesthetic awareness. This study demonstrated that increased kinesthetic awareness resulted in improved motor control [25]. Our study indicated that the 6-week online Pilates exercise program provided a significant improvement in trunk proprioception. This result highlights the effectiveness of online Pilates exercises in preventing proprioceptive losses. As our study shows, online Pilates exercises are an exercise approach that improves trunk proprioception and can be included among the preventive approaches in healthy individuals. Because there are no other studies investigating the effect of Pilates on trunk proprioception, a literature comparison on this subject could not be performed.

Core or trunk muscle strength is important for the successful performance of sports or daily activities [6]. One of the goals of Pilates exercises is to strengthen and train the core muscles for the control of trunk movement in all three planes [26, 27]. Pilates exercises focus on strengthening the core muscles to stabilize the trunk [28]. There are many studies investigating the effects of Pilates exercises on trunk muscle endurance in healthy individuals. A systematic review including 16 randomized controlled trials that examined the effectiveness of Pilates in healthy individuals provided moderate evidence for improving muscular endurance [12]. Nine randomized controlled trials on the effect of Pilates exercises on healthy individuals were discussed in another systematic review. These results demonstrated that Pilates exercises performed two to three times a week for 5-12 weeks increased abdominal muscle endurance in both genders [29]. In another study involving 50 healthy individuals, the participants were divided into control and Pilates groups. While the participants in the Pilates group followed a 1-h Pilates exercise program 2 days a week for 12 weeks, the control group continued their routine activity level. The study showed that trunk flexor muscle endurance increased in the Pilates group [3]. These studies support our results in terms of showing that Pilates exercises increase core muscle endurance in healthy individuals. Our results demonstrated that there was a significant improvement in the Pilates group in all core endurance tests. Although there are studies in the literature showing that Pilates exercises increase core muscle endurance, there is no study investigating the effect of online Pilates exercises on core muscle endurance. In this respect, our study has a unique value.

Telehealth exercise protocols have been developed to assist people living in different conditions [30, 31]. In the COVID-19 pandemic, where people around the world require to be isolated to prevent the spread of the virus, telehealth exercise practices have become more important [32]. Home exercises may be safer than gymnasiums to avoid an increase in pandemic cases [33]. We conducted 
Table 2 Comparison of proprioception and core muscle endurance measurements within and between groups

\begin{tabular}{|c|c|c|c|c|c|c|c|c|}
\hline & & $\begin{array}{l}\text { Pre-test } \\
\text { Median (IQR) }\end{array}$ & $\begin{array}{l}\mathbf{p}^{\mathbf{a}} \\
\text { (between } \\
\text { groups) }\end{array}$ & $\begin{array}{l}\text { Post-test } \\
\text { Median (IQR) }\end{array}$ & $\begin{array}{l}\text { Change } \\
\text { Median (IQR) }\end{array}$ & $\mathbf{p}^{\mathbf{b}}$ (within group) & $\begin{array}{l}\mathbf{p}^{\mathrm{c}} \\
\text { (between } \\
\text { groups) }\end{array}$ & Effect size \\
\hline \multirow[t]{2}{*}{ Proprioception } & PG & $2(1.33-4.33)$ & 0.625 & $1(0.66-1.33)$ & $-1.66(-2.67-0)$ & $0.008^{*}$ & 0.093 & 0.72 \\
\hline & CG & $2.66(2.17-3.33)$ & & $2.66(2-3)$ & $\begin{array}{l}-0.5(-1.17- \\
0.67)\end{array}$ & 0.280 & & 0.30 \\
\hline \multirow[t]{2}{*}{ Trunk flexor test } & PG & $\begin{array}{l}42.76(32.69- \\
55.63)\end{array}$ & 0.505 & $\begin{array}{l}73.9(46.93- \\
94.33)\end{array}$ & $\begin{array}{l}23.05(11.96- \\
48.31)\end{array}$ & $0.001 *$ & $0.009 *$ & 1.11 \\
\hline & CG & $\begin{array}{l}57.04(27.66- \\
112.4)\end{array}$ & & $\begin{array}{l}66.01(21.45- \\
111.15)\end{array}$ & $\begin{array}{l}4.61(-22.61- \\
14.06)\end{array}$ & 0.959 & & 0.04 \\
\hline \multirow[t]{2}{*}{$\begin{array}{l}\text { Trunk extensor } \\
\text { test }\end{array}$} & PG & $\begin{array}{l}34.02(29.45- \\
49.72)\end{array}$ & 0.732 & $\begin{array}{l}66.19(51.44- \\
86.92)\end{array}$ & $\begin{array}{l}29.72(19.21- \\
47.08)\end{array}$ & $0.000 *$ & $0.002 *$ & 1.25 \\
\hline & CG & $\begin{array}{l}45.94(17.96- \\
65.55)\end{array}$ & & $\begin{array}{l}46.20(20.6- \\
71.42)\end{array}$ & $\begin{array}{l}4.98(-2.88- \\
16.75)\end{array}$ & 0.215 & & 0.23 \\
\hline \multirow[t]{2}{*}{$\begin{array}{l}\text { Dom side bridge } \\
\text { test }\end{array}$} & PG & $\begin{array}{l}27.09(15.68- \\
36.48)\end{array}$ & 0.971 & $\begin{array}{l}47.12(34.62- \\
58.3)\end{array}$ & $\begin{array}{l}17.55(12.28- \\
30.64)\end{array}$ & $0.000 *$ & 0.001* & 1.49 \\
\hline & CG & $\begin{array}{l}22.8(15.27- \\
34.74)\end{array}$ & & $\begin{array}{l}26.14(18.87- \\
40.56)\end{array}$ & $\begin{array}{l}-0.5(-5.52- \\
7.78)\end{array}$ & 0.569 & & 0.13 \\
\hline \multirow[t]{2}{*}{$\begin{array}{l}\text { Non-dom side } \\
\text { bridge test }\end{array}$} & PG & $\begin{array}{l}30.26(16.66- \\
39.73)\end{array}$ & 0.652 & $\begin{array}{l}45.73(33.17- \\
\quad 67.5)\end{array}$ & $12.78(7.6-25.44)$ & $0.001 *$ & $0.004 *$ & 1.05 \\
\hline & CG & $\begin{array}{l}23.36(17.79- \\
30.07)\end{array}$ & & $\begin{array}{l}26.90(19.43- \\
38.75)\end{array}$ & $1.66(-5.5-7.04)$ & 0.796 & & 0.16 \\
\hline \multirow[t]{2}{*}{ Prone bridge test } & PG & $\begin{array}{l}34.23(20.45- \\
58.60)\end{array}$ & 0.249 & $\begin{array}{l}44.22(29.73- \\
70.37)\end{array}$ & $\begin{array}{l}12.28(6.14- \\
23.45)\end{array}$ & 0.001* & $0.002 *$ & 0.95 \\
\hline & CG & $\begin{array}{l}20.66(17.25- \\
38.73)\end{array}$ & & $\begin{array}{l}30.46(20.21- \\
39.91)\end{array}$ & $\begin{array}{l}-0.71(-3.76- \\
8.17)\end{array}$ & 0.469 & & 0.21 \\
\hline
\end{tabular}

Data are presented as median (IQR). $* p<0.05$ between two groups for values (Mann Whitney U Test) and within the group after 6 weeks (Wilcoxon test), $\mathrm{p}^{\mathrm{a}}, p$ values of comparison of baseline values between groups; $\mathrm{p}^{\mathrm{b}}, p$ value of the comparison of the pre-test and 6 weeks later within the group; $\mathrm{p}^{\mathrm{c}}, p$ values of comparison of change between groups; $P G$ Pilates group; $C G$ control group; Dom dominant extremity; Nondom non-dominant extremity

our work on an online platform as it may pose a risk to perform breath-focused Pilates exercises face-to-face in the pandemic. Thus, we had the chance to demonstrate the effect of online Pilates exercises performed with a physiotherapist on trunk proprioception and core muscle endurance. Our study revealed that online exercise applications performed with a physiotherapist give positive results even in the home environment, especially without entering closed and crowded environments in the pandemic.

The study was carried out with female participants between the ages of 18 and 25 . The limitation of the study is that individuals from different age groups and male participants were not included. Future studies involving individuals from both sexes and different age groups are needed.

\section{Conclusion}

This study revealed that online Pilates exercises performed at mat level for 6 weeks in healthy individuals had positive effects on trunk proprioception and core muscle endurance. Online Pilates exercises with a physiotherapist are a type of tele-exercise that increases physical activity and provides beneficial gains in situations where it is a risk to be in crowded environments such as the COVID-19 pandemic or when access to exercise centers is not available. Our study is the first study in the literature to examine the effects of Pilates exercises on trunk proprioception. Moreover, it is the first study to reveal the effects of online application of Pilates exercises. There is a requirement for future studies examining the effect of Pilates exercises on trunk proprioception in individuals of different age groups and with different pathologies. To demonstrate whether online Pilates training is as effective as face-to-face Pilates training, additional studies are required to compare online Pilates training with face-to-face Pilates training.

Acknowledgements The authors would like to thank Rabia Seva Ozkan and Seyda Nurbanu Tasolar for their assistance in the study.

Authors' contribution Sinem Suner-Keklik: Creating the idea of the study, reaching the individuals who will participate in the study, making the individuals do exercises within the scope of the study, analyzing the data, and bringing it to the literature. Ayse Numanoglu-Akbas: 
Organizing the study method, creation of evaluation forms, making the necessary evaluations of the individuals for the study, analyzing the data, and bringing them to the literature. Gamze Cobanoglu: Reaching the individuals who will participate in the study, controlling the individuals while doing their exercises, entering the data into the system, and analyzing and converting them into literature. Nihan Kafa: Organizing the study method, entering the data into the system, and bringing the results to the literature. Nevin A. Guzel: Organizing the study method, interpretation of study results, and conversion to literature.

Funding This study was supported with the project number 119S200 within the scope of TÜBITAK 1002 support program. Provided financial support for the supply of devices used for evaluation.

\section{Declarations}

Ethics approval and consent to participate All authors read and approved the final version of the manuscript.

Conflict of interest The authors declare no competing interests.

\section{References}

1. Middleton A, Simpson KN, Bettger JP et al (2020) COVID-19 pandemic and beyond: Considerations and costs of telehealth exercise programs for older adults with functional impairments living at home-Lessons learned from a pilot case study. Phys Ther 100(8):1278-1288. PMID: 32372072. https://doi.org/10.1093/ptj/ pzaa089

2. Shahrbanian S, Alikhani S, Kakavandi MA et al (2020) Physical activity for improving the immune system of older adults during the COVID-19 pandemic. Altern Ther Health Med 26(S2):117125. PMID: 33245704

3. Kloubec JA (2010) Pilates for improvement of muscle endurance, flexibility, balance, and posture. J Strength Cond Res 24(3):661-667. PMID: 20145572. https://doi.org/10.1519/JSC. 0b013e3181c277a6

4. Hides JA, Jull GA, Richardson CA (2001) Long-term effects of specific stabilizing exercises for first-episode low back pain. Spine (Phila Pa 1976) 26(11):e243-e248. PMID: 11389408. https://doi. org/10.1097/00007632-200106010-00004

5. Smith K, Smith E (2005) Integrating Pilates-based core strengthening into older adult fitness programs: implications for practice. Top Geriatr Rehabil 21(1):57-67

6. Behm DG, Drinkwater EJ, Willardson JM et al (2010) The use of instability to train the core musculature. Appl Physiol Nutr Metab 31(1):91-108. PMID: 20130672. https://doi.org/10.1139/H09-127

7. Kulas AS, Schmitz RJ, Shultz SJ et al (2006) Sex-specific abdominal activation strategies during landing. J Athl Train 41(4):381. PMID: 17273462

8. Abdelraouf OR, Abdel-Aziem AA (2016) The relationship between core endurance and back dysfunction in collegiate male athletes with and without nonspecific low back pain. Int J Sports Phys Ther 11(3):337-344. PMID: 27274419

9. Muthukrishnan R, Shenoy SD, Jaspal SS et al (2010) The differential effects of core stabilization exercise regime and conventional physiotherapy regime on postural control parameters during perturbation in patients with movement and control impairment chronic low back pain. Sports Med Arthrosc Rehabil Ther Technol 2(1):12. PMID: 20515453. https://doi.org/10.1186/ $1758-2555-2-13$
10. Learman KE, Myers JB, Lephart SM et al (2009) Effects of spinal manipulation on trunk proprioception in subjects with chronic low back pain during symptom remission. J Manipulative Physiol Ther 32(2):118-126. PMID: 19243723. https://doi.org/10.1016/j.jmpt. 2008.12.004

11. Lee AS, Cholewicki J, Reeves NP et al (2010) Comparison of trunk proprioception between patients with low back pain and healthy controls. Arch Phys Med Rehabil 91(9):1327-1331. PMID: 20801248. https://doi.org/10.1016/j.apmr.2010.06.004

12. Cruz-Ferreira A, Fernandes J, Laranjo L et al (2011) A systematic review of the effects of pilates method of exercise in healthy people. Arch Phys Med Rehabil 92(12):2071-2081. PMID: 22030232. https://doi.org/10.1016/j.apmr.2011.06.018

13. Donahoe-Fillmore B, Hanahan NM, Mescher ML et al (2007) The effects of a home Pilates program on muscle performance and posture in healthy females: a pilot study. J Womens Health Phys Therap 31(2):6-11

14. Sekendiz B, Altun Ö, Korkusuz F et al (2007) Effects of Pilates exercise on trunk strength, endurance and flexibility in sedentary adult females. J Bodyw Mov Ther 11(4):318-326. https://doi.org/ 10.1016/j.jbmt.2006.12.002

15. Emery K, Serres SJD, McMillan A et al (2010) The effects of a Pilates training program on arm-trunk posture and movement. Clin Biomech 25(2):124-130. https://doi.org/10.1016/j.clinbiomech. 2009.10.003

16. Yoo W (2012) Comparison of immediate changes in cervical and lumbar repositioning errors and pain in asymptomatic computer users after computer work. J Phys Ther Sci 24(12):1325-1327

17. Goldberg A, Hernandez ME, Alexander NB (2005) Trunk repositioning errors are increased in balance-impaired older adults. J Gerontol A Biol Sci Med Sci 60(10):1310-1314. PMID: 16282565. https://doi.org/10.1093/gerona/60.10.1310

18. Suner-Keklik S, Cobanoglu-Seven G, Kafa N et al (2017) The validity and reliability of knee proprioception measurement performed with inclinometer in different positions. J Sport Rehabil 26(6). PMID: 28605314. https://doi.org/10.1123/jsr.2017-0010

19. Waldhelm A, Li L (2012) Endurance tests are the most reliable core stability related measurements. J Sport Health Sci 1(2):121128. https://doi.org/10.1016/j.jshs.2012.07.007

20. Cobanoglu G, Suner-Keklik S, Zorlular A et al (2019) The relationship between scapular and core muscle endurance in professional athletes. Ann Med Res 26(7):1295-1300. https://doi.org/ 10.5455/annalsmedres.2019.03.142

21. Cancelliero-Gaiad KM, Ike D, Pantoni CB et al (2014) Respiratory pattern of diaphragmatic breathing and pilates breathing in COPD subjects. Braz J Phys Ther 18(4):291-299. PMID: 25075999. https://doi.org/10.1590/bjpt-rbf.2014.0042

22. Cohen J (1988) Statistical power analysis for the behavioral sciences (2nd ed). Hillsdale, NJ:Erlbaum.

23. Proske U, Gandevia SC (2012) The proprioceptive senses: their roles in signaling body shape, body position and movement, and muscle force. Physiol Rev 92(4):1651-1697. PMID: 23073629. https://doi.org/10.1152/physrev.00048.2011

24. Abboud J, Rousseau B, Descarreaux M (2018) Trunk proprioception adaptations to creep deformation. Eur J Appl Physiol 118(1):133-142. PMID: 29116380. https://doi.org/10.1007/ s00421-017-3754-2

25. Johnson EG, Larsen A, Ozawa H et al (2007) The effects of Pilates-based exercise on dynamic balance in healthy adults. $\mathbf{J}$ Bodyw Mov Ther 11(3):238-242. https://doi.org/10.1016/j.jbmt. 2006.08.008

26. Moreno MA, Catai AM, Teodori RM et al (2007) Effect of a muscle stretching program using the Global Postural Reeducation method on respiratory muscle strength and thoracoabdominal mobility of sedentary young males. J Bras Pneumol 
33(6):679-686. PMID: 18200368. https://doi.org/10.1590/s180637132007000600011

27. Castagnoli C, Cecchi F, Del Canto A et al (2015) Effects in short and long term of Global Postural Reeducation (GPR) on chronic low back pain: a controlled study with one-year follow-up. Sci World J 2015. PMID: 25945360. https://doi.org/10.1155/2015/ 271436

28. Critchley DJ, Pierson Z, Battersby G (2011) Effect of pilates mat exercises and conventional exercise programmes on transversus abdominis and obliquus internus abdominis activity: pilot randomised trial. Man Ther 16(2):183-189. PMID: 21075038. https://doi.org/10.1016/j.math.2010.10.007

29. Campos RR, Dias JM, Pereira LM et al (2016) Effect of the Pilates Method on Physical Conditioning of Healthy Subjects: A Systematic Review and Meta-Analysis. J Sports Med Phys Fitness 56(7-8):864-873. PMID: 26004043

30. Rawstorn JC, Gant N, Direito A et al (2016) Telehealth exercisebased cardiac rehabilitation: a systematic review and meta-analysis. Heart 102(15):1183-1192. PMID: 26936337. https://doi.org/10. 1136/heartjnl-2015-308966
31. Adamse C, Dekker-Van Weering MG, van Etten-Jamaludin FS et al (2018) The effectiveness of exercise-based telemedicine on pain, physical activity and quality of life in the treatment of chronic pain: A systematic review. J Telemed Telecare 24(8):511526. PMID: 28696152. https://doi.org/10.1177/1357633X17 716576

32. Jiménez-Pavón D, Carbonell-Baeza A, Lavie CJ (2020) Physical exercise as therapy to fight against the mental and physical consequences of COVID-19 quarantine: Special focus in older people. Prog Cardiovasc Dis 63(3):386. PMID: 32220590. https://doi.org/ 10.1016/j.pcad.2020.03.009

33. Silva Filho E, Xavier J, Cezarino L et al (2020) Comment on "The importance of physical exercise during the coronavirus (COVID19) pandemic." Rev Assoc Med Bras 66(9):1311-1313. PMID: 33027466. https://doi.org/10.1590/1806-9282.66.9.1311

Publisher's Note Springer Nature remains neutral with regard to jurisdictional claims in published maps and institutional affiliations. 